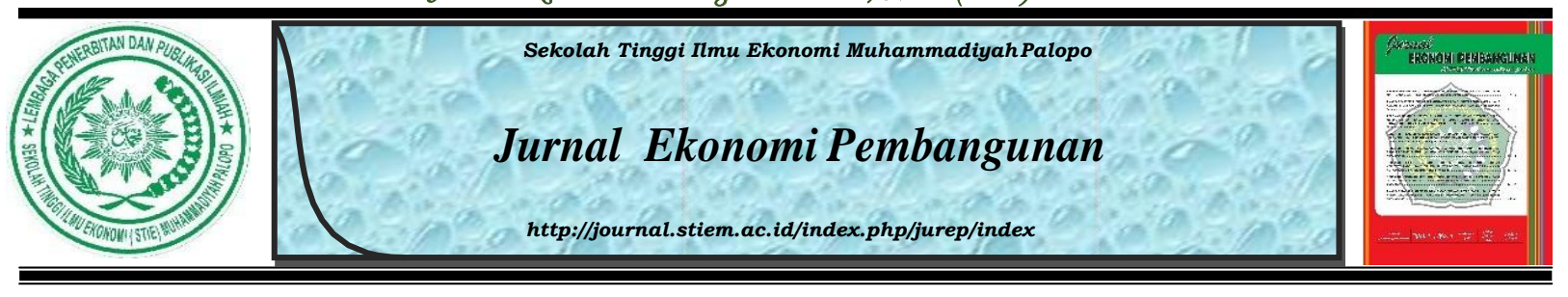

\title{
Pengaruh Modal Dan Luas Lahan Terhadap Produksi Rumput Laut (Glacillaria Sp) Di Desa Lampuara Kecamatan Ponrang Selatan Kabupaten Luwu
}

\author{
Risna $^{1}$, Hasbi Munarka ${ }^{2}$, Muctar Surullah ${ }^{3}$ \\ ${ }^{1,2,3}$ STIE Muhammadiyah Palopo
}

\section{INFO NASKAH}

Diserahkan

O1Mei 2018

Diterima

20 Mei 2018

Diterima dalam revisi

22 Mei 2018

Diterima dan disetujui

11 Juni 2018

Kata Kunci:

Modal, Luas Lahan dan

Pendapatan Petani

\section{ABSTRAK}

Tujuan penelitian untuk mengetahui besarnya modal berpengaruh terhadap peningkatan pendapatan petani rumput laut di Desa Lampuara Kecamatan Ponrang Selatan Kabupaten Luwu. Dan untuk mengetahui luas lahan berpengaruh terhadap peningkatan pendapatan petani rumput laut di Desa Lampuara Kecamatan Ponrang Selatan Kabupaten Luwu. Melalui pembagian kuesioner kepada para petani sebanyak 30 orang yang menjadi responden, kemudian diuji dengan menggunakan spss dengan metode analisis regresi berganda, hasil pengujian hipotesis menunjukka bahwa variabel modal berpengaruh terhadap pendapatan petani dibuktikan dengan hasil uji spss yaitu nilai coefficients beta sebesar 0,293 dengan nilai signifikan 0,002 yang lebih kecil dari tingkat signifikan yaitu 0,05 , yang artinya berpengaruh signifikan dan variabel luas lahan berpengaruh terhadap pendapatan petani dengan hasil nilai coefficients beta sebesar 0,385 dengan nilai signifikan 0,004 yang lebih kecil dati tingkat signifikan yaitu 0,05 yang artinya signifikan. Jadi kesimpulannya adalah modal dan luas lahan berpengaruh signifikan terhadap pendapatan petani rumput laut pada Desa Lampuara Kecamatan Ponrang Selatan Kabupaten Luwu. 


\section{Pendahuluan}

Pembangunan yang sedang dilaksanakan bangsa Indonesia seperti yang tercantum dalam pembukaan Undang-undang 1945 dimaksud untuk mencapai tujuan nasional, yang selanjutnya dijabarkan dalam garis-garis Besar Haluan Negara melalui Tap MPR No. II/ MPR/ 1993 yaitu untuk mewujudkan masyarakat adil dan makmur berdasarkan Pancasila dalam wadah Negara Kesatuan Republik Indonesia.

Sedangkan pembangunan daerah adalah sebagai bagian integral dari pembangunan nasional diarahkan untuk menunjang pembangunan daerah dan menyerasikan laju pertumbuhan ekonomi antar daerah, antar kota, dan antar sektor ekonomi. Dalam upaya peningkatan laju pertumbuhan ekonomi, maka pembangunan tersebut bertitik tolak pada potensi wilayah yang bersangkutan. Pembangunan daerah ini bertujuan meningkatkan tarap hidup dan kesejahteraan masyarakat melalui pembangunan yang serasi dan terpadu baik antar sektor maupun pembangunan sektoral dengan perencanaan pembangunan oleh daerah secara efisien dan efektif menuju terciptanya kemandirian daerah tersebut.

Untuk mencapai tujuan tersebut tidak terlepas dari peranan sektor pertanian. Di mana sektor ini memberikan kontribusi yang cukup besar terhadap peningkatan pertumbuhan Produk Domestik Bruto (PDB) Kabupaten Luwu. Salah satu sub-sektor pertanian yang baru mulai dinikmati hasilnya oleh petani adalah pembangunan rumput laut. Pengembangan rumput laut ini memberikan dampak yang lebih nyata dan memaksimalkan pembangunan pertanian sub-sektor terhadap perubahan tingkat hidup masyarakat, khususnya petani tambak, maka upaya yang perlu ditempuh ditunjukan pada usaha untuk meningkatkan pertumbuhan produksi melalui usaha pertanian yang lebih produktif, dengan menerapkan metode ilmiah, serta membuka pasar yang lebih luas.

Adapun maksud dari tujuan penelitian ini adalah untuk mengetahui besarnya modal berpengaruh terhadap peningkatan pendapatan petani rumput laut di Desa Lampuara Kecamatan Ponrang Selatan Kabupaten Luwu dan luas lahan berpengaruh terhadap peningkatan pendapatan petani rumput laut di Desa Lampuara Kecamatan Ponrang Selatan Kabupaten Luwu.

\section{Metode Penelitian}

\subsection{Pendekatan Penelitian}

Metode pengumpulan data yang digunakan dalam penelitian ini adalah:

a. Kuesioner 
Metode pengumpulan data yang digunakan dalam penelitian ini adalah dengan menggunakan alat berupa koesioner. Kuesioner adalah teknik pengumpulan data melalui daftar pertanyaan dengan jumlah pilihan jawaban yang ditetapkan oleh peneliti.

b. Wawancara

Metode pengumpulan data yang digunakan dalam penelitian ini adalah teknik pengumpulan data yang diperoleh dengan melalui percakapan langsung dengan responden serta dengan pihak-pihak lain yang terkait dengan objek.

\subsection{Populasi dan Sampel}

Populasi dan sampel yang digunakan dalam penelitian ini adalah sebagai berikut:

a. Populasi

Populasi dalam penelitian ini adalah jumlah petani rumput laut yang ada di Desa Lampuara Kecamatan Ponrang Selatan Kabupaten Luwu yang berjumlah 30 orang.

b. Sampel

Karena jumlah populasi yang sedikit maka pengambilan sampel dalam penelitian ini dilakukan secara sensus yakni seluruh jumlah petani rumput laut yang akan dijadikan sampel.

\subsection{Teknik Analisis Data}

Analisis regresi linier berganda adalah hubungan secara linear antara dua atau lebih variabel independen $\left(\mathrm{X}_{1}, \mathrm{X}_{2}, \ldots\right)$ dengan variabel dependen $(\mathrm{Y})$. Analisis ini untuk mengetahui arah hubungan antara variabel independen dengan variabel dependen apakah masing-masing variabel independen berhubungan signifikan atau tidak signifikan dan untuk memprediksi nilai dari variabel dependen apabila nilai variabel independen mengalami kenaikan atau penurunan

Persamaan regresi linear berganda dalam penelitian ini sebagai berikut:

$$
\mathrm{Y}=\alpha+b_{1} X_{1}+b_{2} X_{2}+e
$$

Dimana :

$$
\begin{aligned}
\mathrm{Y} & =\text { Pendapatan } \\
\mathrm{X} 1 & =\text { Modal } \\
\mathrm{X} 2 & =\text { Luas Lahan } \\
\mathrm{A} & =\text { Intercept/Konstanta } \\
\mathrm{b} & =\text { Koefisien Regresi } \\
e & =\text { Term of error (Kesalahan Pengganggu) }
\end{aligned}
$$




\section{Hasil dan Pembahasan}

\subsection{Hasil}

\section{a. Karakteristik Responden Berdasarkan Umur}

Karakteristik Responden Berdasarkan Umur adalah gambaran tentang responden menurut umur masing- masing responden. Karakteristik responden berdasarkan usia dibagi menjadi 4 (empat) kelompok yakni, umur $<30$ tahun, 31-40 tahun, 41-50 tahun dan $>50$ tahun.

Karakteristik responden berdasarkan usia ini dapat kita lihat pada Tabel 4.1 berikut ini.

Tabel 4.1

Karakteristik Responden Berdasarkan Umur

\begin{tabular}{|l|l|l|l|}
\hline No & Usia & Jumlah & Persentase \\
\hline 1. & $<30$ Tahun & 1 & $3,3 \%$ \\
\hline 2. & $31-40$ Tahun & 7 & $23,3 \%$ \\
\hline 3. & $41-50$ Tahun & 13 & $43,3 \%$ \\
\hline 4 & $>50$ & 9 & $30 \%$ \\
\hline & Jumlah & 30 & $100 \%$ \\
\hline
\end{tabular}

Sumber data diolan tahun 2018

Pada Tabel 4.1 di atas dapat diketahui responden berusia $<30$ tahun berjumlah 1 orang atau sekitar 3,3\%, responden yang berusia 31-40 tahun berjumlah 7 orang atau sekitar 23,3 $\%$ jumlah responden yang berusia 41-50 tahun berjumlah 13 atau sekitar 43,3\% dan jumlah responden yang berusia $>50$ tahun berjumlah 9 orang atau sekitar $30 \%$ berdasarkan data di atas responden berdasarkan usia dominam pada 41-50 Tahun.

\section{b. Karakteristik Responden Berdasarkan Jenis Kelamin}

Karakteristik responden berdasarkan jenis kelamin adalah gambaran tentang responden menurut jenis kelamin masing-masing responden. Karakteristik responden berdasarkan jenis kelamin dibagi menjadi 2 (dua) kelompok yakni laki-laki dan perempuan .

Karakteristik responden berdasarkan jenis kelamin ini dapat kita lihat pada Tabel 4. 2 berikut ini. 
Tabel 4.2

\section{Karakteristik Responden Berdasarkan Jenis Kelamin}

\begin{tabular}{|l|l|l|l|}
\hline No. & \multicolumn{1}{|c|}{ Jenis Kelamin } & Jumlah & Persentase \\
\hline 1. & Laki-Laki & 27 & $90 \%$ \\
\hline 2. & Perempuan & 3 & $10 \%$ \\
\hline & Jumlah & 30 & $100 \%$ \\
\hline
\end{tabular}

Sumber: data diolah, 2018

Pada Tabel 4.2 dapat diketahui bahwa responden berjenis kelamin laki-laki berjumlah 27 orang atau sekitar $90 \%$ dari se3luruh jumlah responden, sedangkan yang berjenis kelamin perempuan sebanyak 3 orang atau sekitar $10 \%$ dari keseluruhan responden, berdasarkan data yang diperoleh hasil menunjukkan bahwa dominan laki-laki yaitu 27 orang.

\section{c. Karakteristik Responden Berdasarkan Tingkat Pendidikan Terakhir}

Karakteristik responden berdasarkan tingkat pendidikan terakhir adalah gambaran tentang responden menurut pendidikan terakhir yang pernah diikuti oleh masing-masing responden. Karakteristik responden berdasarkan tingkat pendidikan terakhir dibagi jadi 4 (empat) kelompok yaitu SD, SMP, SMA, dan strata satu ( S1 ).

Karakteristik responden berdasarkan tingkat pendidikan terakhir dapat dilihat pada Tabel berikut.

Tabel 4.3

Karakteristik Responden Berdasarkan Pendidikan Terakhir

\begin{tabular}{|l|l|l|l|}
\hline No. & Pendidikan Terakhir & Jumlah & Persentase \\
\hline 1 & SD & 14 & $46,7 \%$ \\
\hline 2 & SMP & 7 & $23,3 \%$ \\
\hline 3 & SMA & 7 & $23,3 \%$ \\
\hline 4 & S1 & 2 & $6,7 \%$ \\
\hline & Jumlah & 30 & $100 \%$ \\
\hline
\end{tabular}

Sumber: data diolah tahun 2018

Data pada Tabel 4.3 dapat diketahui bahwa responden yang berpendidikan terakhir SD berjumlah 14 orang atau sekitar 46,7\%, SMP berjumlah 7 orang atau sekitar 23,3\%, SMA 
berjumlah 7 orang atau sekitar 23,3\%, dan S1 berjumlah 2 orang atau sekitar 6,7\%, dari seluruh jumlah responden. Dari jumlah responden yang berpendidikan SD yang lebih dominan.

\subsection{Analisis Regresi Linear Berganda}

Analisis regresi linier berganda digunakan untuk mengetahui bagaimana hubungan antara ketiga sub variabel, dalam hal ini variabel modal, luas lahan, dengan pendapatan. Berdasarkan hasil pengolahan data yang telah dilakukan dengan menggunakan SPSS V.21 for windows, maka hasilnya secara lengkap disajikan dalam Tabel 4.9 di bawah ini :

\section{Tabel 4.9}

\section{Hasil regresi linear berganda}

\begin{tabular}{|c|c|c|c|c|c|}
\hline \multirow[t]{2}{*}{ Model } & \multicolumn{2}{|c|}{$\begin{array}{l}\text { Unstandardized } \\
\text { Coefficients }\end{array}$} & $\begin{array}{l}\text { Standardized } \\
\text { Coefficients }\end{array}$ & \multirow[t]{2}{*}{$\mathrm{T}$} & \multirow[t]{2}{*}{ Sig. } \\
\hline & B & Std. Error & Beta & & \\
\hline (Constant & 5,422 & 2,102 & & 2,579 & ,016 \\
\hline ) & & & & & \\
\hline $\mathrm{X} 1$ & ,293 & ,086 & ,475 & 3,417 & ,002 \\
\hline $\mathrm{X} 2$ &, 385 &, 124 & ,433 & 3,111 & ,004 \\
\hline
\end{tabular}

a. Dependent Variable: Y

Sumber: data diolah tahun 2018

Dari Tabel 4.9 di atas diperoleh persamaan regresi linear berganda pada penelitian ini adalah sebagai berikut:

$$
\mathrm{Y}=5,422+0,293 \mathrm{X}_{1}+0,385 \mathrm{X}_{2}
$$

Persamaan regresi tersebut memperlihatkan bahwa modal dan luas lahan dianggap konstan maka modal akan naik sebesar 0,293. Apabila variabel modal naik sebesar 1\% sedangkan variabel lain (modal) dianggap konstan maka pendapatan naik sebesar 5,422. Apabila variabel luas lahan naik sebesar 1\% sedangkan variabel lain (luas lahan) dianggap konstan maka pendapatan naik sebesar 0,336 . 


\subsection{Analisis Koefisien Determinasi}

Koefisien determinasi digunakan untuk mengetahui seberapa besar tingkat pengaruh atau tinggi rendahnya pengaruh antara modal dan luas lahan sebagai variabel independen terhadap pendapatan sebagai variabel dependen. $\mathrm{R}$ Square $\left(\mathrm{R}^{2}\right)$ berguna untuk mengetahu pengaruh variabel independen terhadap variabel dependen, seperti yang disajikan pada Tabel 4.10 berikut:

Tabel 4.10

Nilai koefisien determinasi Model Summary

\begin{tabular}{|l|l|l|l|l|}
\hline Model & R & R Square & $\begin{array}{l}\text { Adjusted } \\
\text { Square }\end{array}$ & $\begin{array}{l}\text { Std. Error of the } \\
\text { Estimate }\end{array}$ \\
\hline 1 &, $708^{\mathrm{a}}$ &, 501 &, 464 &, 75665 \\
\hline
\end{tabular}

a. Predictors: (Constant), X2, X1

Sumber: Data diolah tahun 2018

Hasil Tabel 4.10 menunjukkan bahwa $\mathrm{R}$ square sebesar 0,501 yang artinya bahwa variabel independen (modal dan luas lahan) memberikan pengaruh sebesar 50,1\% terhadap variabel dependen (pendapatan), dilihat dari interval koefisien menunjukkan tingkat hubungan yang tinggi antara variabel independen terhadap variabel dependen. Sedangkan sisanya sebesar 40,9\% dipengaruhi oleh faktor lain yang tidak diteliti oleh penulis.

\subsection{Pengujian Hipotesis}

\section{a. Uji t}

Uji t digunakan untuk mengetahui signifikan atau tidaknya suatu pengaruh variabel independen secara parsial atas variabel dependen. Untuk menguji hipotesis tersebut maka terlebih dahulu menentukan kriteria tingkat signifikan yaitu sebesar 5\%=0,05 kemudian dibandingkan dengan hasil signifikan yang telah diolah menggunakan program SPSS V.21 output uji t pada Tabel 4.11 berikut: 
Tabel 4.11

\section{Hasil Regresi Uji t}

\begin{tabular}{|l|l|l|l|l|l|}
\hline Model & \multicolumn{2}{|l|}{$\begin{array}{l}\text { Unstandardized } \\
\text { Coefficients }\end{array}$} & $\begin{array}{l}\text { Standardized } \\
\text { Coefficients }\end{array}$ & T & Sig. \\
\cline { 2 - 5 } & B & Std. Error & Beta & & \\
\hline (Constant) & 5,422 & 2,102 & & 2,579 &, 016 \\
1 X1 &, 293 &, 086 &, 475 & 3,417 &, 002 \\
X2 &, 385 &, 124 &, 433 & 3,111 &, 004 \\
\hline
\end{tabular}

a. Dependent Variable: Y

Sumber: Data diolah tahun 2018

Berdasarkan nilai uji $\mathrm{t}$ yang diperoleh secara parsial dan perhitungan $t_{\text {tabel }}$ dengan kriteria tingkat signifikan sebesar 0,05 dan derajat kebebasan $(\mathrm{dk})=\mathrm{n}-\mathrm{k}-1$ atau 30-2-1=27 ( $\mathrm{n}$ adalah jumlah sampel dan $\mathrm{k}$ adalah jumlah variabel independen), maka diperoleh $\mathrm{t}_{\text {tabel }}$ sebesar 2,052. Berdasarkan nilai uji t yang diperoleh, secara persial pengaruh variabel independen terhadap variabel dependen adalah sebagai berikut:

1) Modal diperoleh $t_{\text {hitung }}$ sebesar 3,417 dan $t_{\text {tabel }}$ sebesar 2,052 , maka diperoleh hasil $t_{\text {hitung }}>$ $\mathrm{t}_{\text {tabel }}$ atau 3,417 > 2,026 dengan tingkat signifikan sebesar 0,002 > 0,05 yang artinya $\mathrm{H}_{1}$ diterima dan $\mathrm{H}_{0}$ ditolak, dengan kata lain terdapat pengaruh yang signifikan antara modal dan pendapatan.

2) Luas lahan diperoleh $t_{\text {hitung }}$ sebesar 3,111 dan $t_{\text {tabel }}$ sebesar 2,052, maka diperoleh hasil $\mathrm{t}_{\text {hitung }}>\mathrm{t}_{\text {tabel }}$ atau 3,111>2,052 dengan tingkat signifikan sebesar 0,004, < 0,05 yang artinya $\mathrm{H}_{2}$ diterima dan $\mathrm{H}_{0}$ ditolak, dengan kata lain terdapat pengaruh yang signifikan antara luas lahan dengan modal.

\section{b. Uji F}

Uji F digunakan untuk menguji koefisien regresi secara keseluruhan dan untuk mengetahui keberartian hubungan antara variabel independen secara bersama-sama dengan variabel dependen. Pengujian hipotesis akan menggunakan tingkat signifikasi sebesar 5\%= 0,05. Hasil penelitian dengan menggunakan program SPSS V.21 dapat dilihat pada Tabel 4.12 berikut: 
Tabel 4.12

\section{Hasil regresi uji F}

ANOVA ${ }^{\mathrm{a}}$

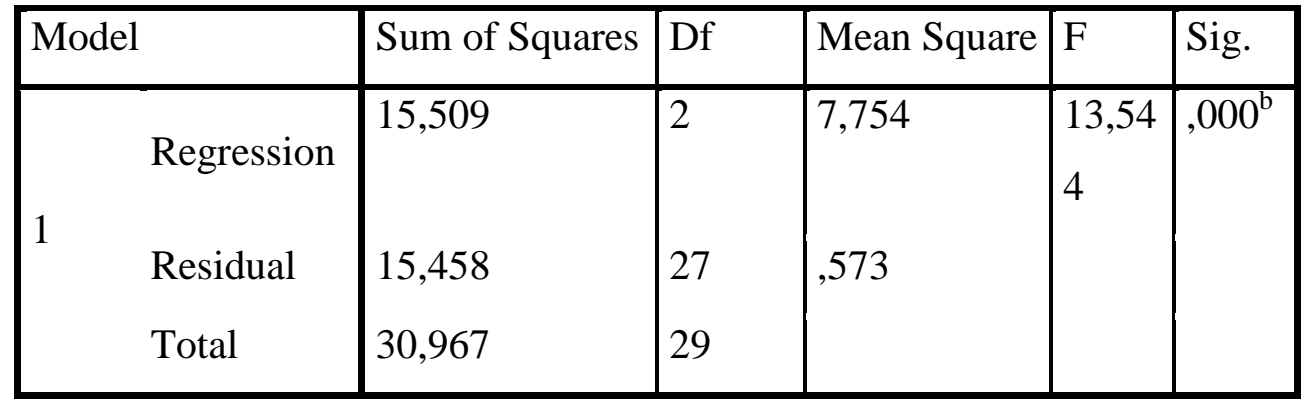

a. Dependent Variable: Y

b. Predictors: (Constant), X2, X1

Sumber: Data diolah tahun 2018

Hasil regresi uji $\mathrm{F}$ Tabel 4.12 memperlihatkan nilai $\mathrm{F}_{\text {hitung }}$ sebesar 13,544 nilai ini yang akan menjadi statistik uji yang akan dibandingkan dengan nilai $\mathrm{F}_{\text {tabel }}$ yang dihitung dengan $\mathrm{df}_{1}($ derajat bebas pembilang $)=2 \mathrm{dan} \mathrm{df}_{2}($ derajat bebas penyebut $)=30$ maka diperoleh $\mathrm{f}_{\text {tabel }}$ sebesar 3,32. Berdasarkan nilai $F_{\text {hitung }}$ dan nilai $F_{\text {tabel }}$ yang telah didapat maka $F_{\text {hitung }}>$ $F_{\text {tabel }}$ atau 13,544 > 3,32 dengan tingkat signifikan sebesar $0.000<0,05$ yang artinya $\mathrm{H}_{\mathrm{a}}$ diterima dan $\mathrm{H}_{0}$ ditolak. Dengan kata lain bahwa secara simultan (bersama-sama) pengaruh modal dan luas lahan berpengaruh signifikan terhadap produksi rumput laut.

\section{Simpulan dan Saran}

Berdasarkan hasil penelitian maka dapat di tarik kesimpulan sebagai berikut :

a. Modal secara langsung berpengaruh signifikan terhadap pendapatan hasil tani rumput laut pada Desa Lampuara Kecamatan Ponrang Selatan Kabupaten Luwu . Hal ini menunjukkan bahwa semakin banyak modal yang kita gunakan maka semakin tinggi pula pendapatan yang dihasilkan oleh petani rumput laut, itu di tunjukkan dari hasil uji SPPS 0,002 yang lebih kecil dari tingkat signifikan yaitu 0,05 .

b. Luas lahan secara langsung berpengaruh signifikan terhadap pendapatan hasil tani rumput laut pada Desa Lampuara Kecamatan Ponrang Selatan Kabupaten Luwu . Hal ini menunjukkan bahwa semakin luas lahan yang digunakan maka semakin banyak pula penghasilan yang bisa di dapatakan oleh petani rumput laut, itu di 
tunjukkan dari hasil uji SPPS 0,004 yang lebih kecil dari tingkat signifikan yaitu 0,05 .

Berdasarkan hasil penelitian ini, maka penulis mengajukan beberapa saran sebagai berikut:

a. Diharapkan kepada petani tambak agar memperhatikan beberapa hal tersebut agar dapat meningkatkan penghasilan para petani

b. Diharapkan pemerintah memberikan bantuan kepada masyarakat khususnya para petani rumput laut agar mereka dapat meningkatkan penghasilan yang dapat mencukupi kehidupan sehari dalam keluarga.

c. Penulis menyadari bahwa banyak hal yang kurang dalam penelitian ini sehingga penulis menyarankan kepada para peneliti berikutnya untuk menambahkan apa yang kurang dari penelitian ini agar lebih sempurna lagi. 


\section{Daftar Pustaka}

Anonimus. 1999. Budidaya Pengelolaan dan Pemasaran Rumput Laut, penerbit, PT. Penebar Swadaya.

Anwas Adiwilguna, 1992. Pengantar Ilmu Peritanian, Rineke Cipta, Jakarta.

Aslan, Laode. 1997. Budidaya Rumput Laut, Penerbit. Kanisus IKIP Yogyakarta.

Basmal, J. 2001. Perkembangan Teknologi Riset Penangan Pasca Panen dan Industri Rumput Laut . Jakarta: Pusat Riset.

Bambang Riyanto, 1991. Dasar-dasar Pembelanjaan Perusahaan (Yogyakarta: Yayasan Badan Penerbit UGM).

Bengen, DG. 2004. Sinopsis Ekosistem dan Sumber Daya Alam Pesisir dan Laut serta Prinsip Pengelolaannya.

Boediono 1992. Pengantar Ilmu Pertanian, Rineke Cipta Jakarta.

Dahuri, R., J. Rais, S.P. Ginting dan M. J. Sitepu. 2001. Pengelolaan Sumber Daya Wilayah Pesisir dan Lautan secara terpadu. Jakarta. PT Pradnya Paramita.

Dahuri, et,al . 2005. Potensi Ekonomi Kelautan (Menyambut Hari Nusantara 13 Desember). Republika, Selasa, 13 Desember 2005.

Haslett SK. 2000. Coastal System. Rout Ledgen Introduction to Environment.

Hermanto, 1995. Pengelolaan Hasil Pertanian Intermedia, Jakarta.

Kay, R dan Alder. 2005. Coastal Planningand Management Taylor and Francis. Landon and York.

Kusnadi, 2003. Akar Kemiskinan Nelayan. LKiS, Yogyakarta.

Kadarsan, Halimah W. 1995. Keuangan Pertanian dan Pembiayaan Perusahaan Agribisnis.PT. Gramedia Pustaka Umum. Jakarta.

Lipsey, Richard G. 1991. Pengantar Ilmu Makro Ekonomi. Ahli Bahasa: Jaka Wasana dkk. Erlangga, Jakarta.

Mosher. A. T (1991). Mengerakan dan Membangun Pertanian. Jakarta Jasa Guna. (1995). Pertanian (Agrikultur) cetakan kelima, Bina Aksara. Jakarta.

Mubarak H, Soegarto A, Sulistyo, Admadja WS. 1990. Petunjuk Teknis Budidaya Rumput Laut.

Mubyarto, (1998 : 195). Pengantar Ekonomi Pertanian, Penerbit. LP3ES.

Mulyadi 1993. Teori Biaya dan Produksi, L3ts- UI - Jakarta.

Nasution, Rusdiah 2008. Pengaruh Modal Kerja, Luas Lhan Tehadap Pendaptan Usaha Tani. 
Pass, Cristopher dan Lowes, Briyan. 1994. Kamus Lengkap Ekonomi. Edisi ke-2. Erlangga, Jakarta. Sadono Sukirno, (2008). Mikro Ekonomi Makro : Teori Pengantar, Jakarta : PT. Raja Goufindo Persada.

Samuelson, Paul A dan William D Nordhaus. 2003. Makro Ekonomi. Edisi 14, Jakarta: Erlangga.

Slamet, 2000. Agrikultur, LPN-IPB-Bogor.

Sumitro Djojohadi Kusumo. (1987:36). Ekonomi Umum I dan Kebijaksanaan. Cetakan Ketiga, Penerbit. -RF Pembangunan.

Supranto, J, (1989). Ekonometrik, Penerbit. LP3ES.

(1997). Statistik Pendapatan Nasional dan Aplikasi Pembangunan Ghalia Indonesia, Jakarta.

Supriharyono, 2000. Pelestarian dan Pengelolaan Sumber Daya Alam di Wilayah Pesisir Tropis. PT. Gramedia Pustaka Utama. Jakarta.

Winardi. 1997. Teori Ekonomi Makro, Cetakan Kedua, Bandung : Taristo.

Zamhuri, M. Yusri 2013. Income Structure and Poverty Of Seaweed Farm Household in Indonesia: A Path Of Casual Model for Poverty Allevation. 